\title{
Activation energy for fluorine transport in amorphous silicon
}

\author{
G. R. Nash and J. F. W. Schiz \\ Department of Electronics and Computer Science, University of Southampton, \\ Southampton SO17 1BJ, England \\ C. D. Marsh \\ Department of Materials, University of Oxford, Oxford OX1 3PH, England \\ P. Ashburn ${ }^{\text {a) }}$ \\ Department of Electronics and Computer Science, University of Southampton, \\ Southampton SO17 1BJ, England \\ G. R. Booker \\ Department of Materials, University of Oxford, Oxford OX1 3PH, England
}

(Received 24 June 1999; accepted for publication 15 October 1999)

\begin{abstract}
The transport of ion-implanted $\mathrm{F}$ in amorphous $\mathrm{Si}$ is studied using secondary ion mass spectroscopy and transmission electron microscopy. Significant redistribution of $\mathrm{F}$ is observed at temperatures in the range $600-700{ }^{\circ} \mathrm{C}$. The measured $\mathrm{F}$ depth profiles are modeled using a simple Gaussian solution to the diffusion equation, and the diffusion coefficient is deduced at each temperature. An activation energy of $2.2 \mathrm{eV} \pm 0.4 \mathrm{eV}$ for $\mathrm{F}$ transport is extracted from an Arrhenius plot of the diffusion coefficients. It is shown that the F transport is influenced by implantation-induced defects. (C) 1999 American Institute of Physics. [S0003-6951(99)03249-0]
\end{abstract}

In recent years, the incorporation of fluorine into various kinds of silicon devices has been shown to be beneficial and has attracted considerable interest. For example, F implanted into polysilicon emitters of bipolar transistors increases the breakup of the thin interfacial oxide that invariably occurs between the polysilicon emitter and underlying single-crystal silicon. ${ }^{1,2}$ Breakup of this oxide layer is required for low values of emitter resistance, and the use of $\mathrm{F}$ enables lower thermal budgets to be used during processing. ${ }^{3,4}$ In metaloxide-semiconductor (MOS) devices, F implanted into the polysilicon gate decreases carrier trapping at the oxide/ silicon interface, leading to improved device performance and increased device lifetimes. ${ }^{5-7}$ Polysilicon is now often deposited as amorphous silicon due to the lower deposition temperature that can be used, and larger grain size and smaller series resistance that result after annealing. ${ }^{8}$

There is relatively little experimental data in the literature on fluorine transport in amorphous, polycrystalline, or single-crystal silicon. Tsai et al. ${ }^{9}$ presented $\mathrm{F}$ depth profiles in high-dose $\mathrm{BF}_{2}$-implanted single-crystal $\mathrm{Si}$ and showed that significant transport of $\mathrm{F}$ occurred during annealing in the temperature range $500-1100{ }^{\circ} \mathrm{C}$. Jeng et al. ${ }^{10}$ and Szeles et al. ${ }^{11}$ reported similar behavior in low-dose F-implanted single-crystal $\mathrm{Si}$, where the implanted $\mathrm{F}$ dose was below the amorphization threshold. No values of the F diffusion coefficient or activation energy were given in any of this work. ${ }^{9-11}$ Recently, Marsh et al. ${ }^{12}$ have shown that $\mathrm{F}$ transport in F- and As-implanted polysilicon is affected by both the formation of inclusions and the As distribution during annealing at $950^{\circ} \mathrm{C}$. An effective diffusion coefficient of $\sim 6 \times 10^{-11} \mathrm{~cm}^{2} / \mathrm{s}$ for $\mathrm{F}$ in polysilicon at $950{ }^{\circ} \mathrm{C}$ was reported. In this work, we investigate $\mathrm{F}$ transport in amorphous

\footnotetext{
a) Author to whom correspondence should be addresssed; electronic mail: pa@ecs.soton.ac.uk
}

$\mathrm{Si}$ in the range $600-700{ }^{\circ} \mathrm{C}$, and extract an activation energy for $\mathrm{F}$ transport of $2.2 \mathrm{eV} \pm 0.4 \mathrm{eV}$. $\mathrm{F}$ depth profiles, measured using secondary ion mass spectroscopy (SIMS), are modeled to give values of the diffusion coefficient at each temperature. Transmission electron microscopy (TEM) studies show that the $\mathrm{F}$ transport is influenced by implantation-induced defects, as previously reported. ${ }^{9,11-16}$

Unpatterned single-crystal $p$-type (B-doped) $\mathrm{Si}(100)$ wafers, with a resistivity of $17-33 \Omega \mathrm{cm}$, were given a HF dip etch. Amorphous silicon was then deposited on the wafers at $560^{\circ} \mathrm{C}$ using a conventional low-pressure chemical-vapor deposition (LPCVD) furnace to give layers of nominal thickness $200 \mathrm{~nm}$, and $\mathrm{F}^{+}$was implanted at room temperature at an energy of $30 \mathrm{keV}$ and a dose of $5 \times 10^{15} \mathrm{~cm}^{-2}$. Finally, a $600 \mathrm{~nm} \mathrm{LPCVD} \mathrm{SiO}_{2}$ capping layer was deposited at $400^{\circ} \mathrm{C}$, and the wafers were sawn into $15 \mathrm{~mm} \times 15 \mathrm{~mm}$ samples. The samples were attached to a silicon susceptor and given a $30 \mathrm{~s}$ rapid thermal anneal in nitrogen, at temperatures in the range $600-700{ }^{\circ} \mathrm{C}$. The $\mathrm{SiO}_{2}$ capping layer was then removed and SIMS analysis was performed using $\mathrm{O}_{2}{ }^{+}$primary ion bombardment and positive secondary ion detection, with the depth scales determined by measuring the sputtered crater depths using interference microscopy. The TEM crosssectional analysis was performed using a Philips CM20 microscope operated at $200 \mathrm{keV}$.

Fluorine SIMS profiles for the as-implanted sample, and samples given a $30 \mathrm{~s}$ rapid thermal anneal (RTA) at temperatures between 600 and $630^{\circ} \mathrm{C}$, are shown in Fig. 1(a). For all the profiles shown in Fig. 1, some data points have been omitted for clarity. SIMS points near the surface are also not shown due to the unreliability of the SIMS measurements in this region. Even after the lowest temperature anneal at $600{ }^{\circ} \mathrm{C}$ there is significant movement of the $\mathrm{F}$ compared with the as-implanted case. The F distribution obtained after annealing has been fitted to a Gaussian profile that models the 


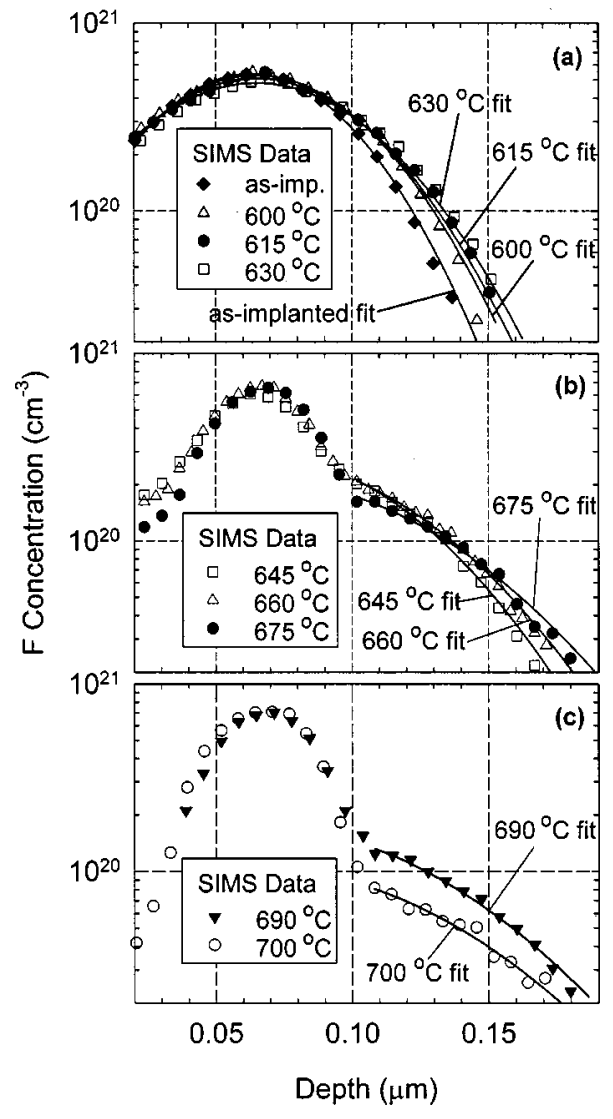

FIG. 1. Fluorine SIMS profiles for amorphous silicon samples implanted with $5 \times 10^{15} \mathrm{~cm}^{-2} \mathrm{~F}^{+}$(a) as implanted and annealed for $30 \mathrm{~s}$ at $600-$ $630{ }^{\circ} \mathrm{C}$, (b) annealed for $30 \mathrm{~s}$ at $645-675^{\circ} \mathrm{C}$, and (c) annealed for $30 \mathrm{~s}$ at 690 and $700^{\circ} \mathrm{C}$. Solid lines are Gaussian fits to the SIMS data.

redistribution of the as-implanted profile due to diffusion: ${ }^{17}$

$N(x, t)=\frac{Q}{\sqrt{2 \pi} \sqrt{2 D_{\mathrm{F}}(T) t+\sigma^{2}}} \exp \left[-\frac{(x-R)^{2}}{2 \sigma^{2}+4 D_{\mathrm{F}}(T) t}\right]$,

where $N(x, t)$ is the F concentration, $x$ is the depth, and $t$ is the anneal time (30 s). $R$ and $\sigma$ are the range and standard deviation of the $\mathrm{F}$ implant, respectively. Values for $R(63$ $\mathrm{nm})$ and $\sigma(32 \mathrm{~nm})$ were derived by fitting Eq. (1), with $t$ $=0$, to the as-implanted $\mathrm{F}$ depth profile. $D_{\mathrm{F}}(T)$ is the $\mathrm{F}$ diffusion coefficient and $Q$ is the $\mathrm{F}$ dose in the layer. Equation (1) was fitted to the measured SIMS profiles using a leastsquares-fitting routine, based on the Levenberg-Marquardt method, and the calculated profiles obtained are shown as solid lines in Fig. 1(a). The dose $Q$ and diffusion coefficient $D_{\mathrm{F}}(T)$ were used as fitting parameters.

SIMS profiles obtained from samples annealed at 645$675^{\circ} \mathrm{C}$ are shown in Fig. 1(b). The broadening of the Gaussian-like tails of the SIMS F profiles with increasing temperature is evidence of thermally activated transport in the $\mathrm{F}$ profile tails. There is also evidence of $\mathrm{F}$ trapping around the implantation peak. In these samples, the $\mathrm{F}$ concentrations at the implantation peak $\left(\sim 7 \times 10^{20} \mathrm{~cm}^{-3}\right)$, and $\sim 0.02 \mu \mathrm{m}$ on either side of the peak, are larger than the concentration at the original as-implanted peak $(\sim 5.5$ $\times 10^{20} \mathrm{~cm}^{-3}$ ). Two transport processes are, therefore, evident: one in the profile tails, and one around the implant peak. For samples annealed at higher temperatures, Fig. 1(c), F trapping around the implant peak appears to be the stron-

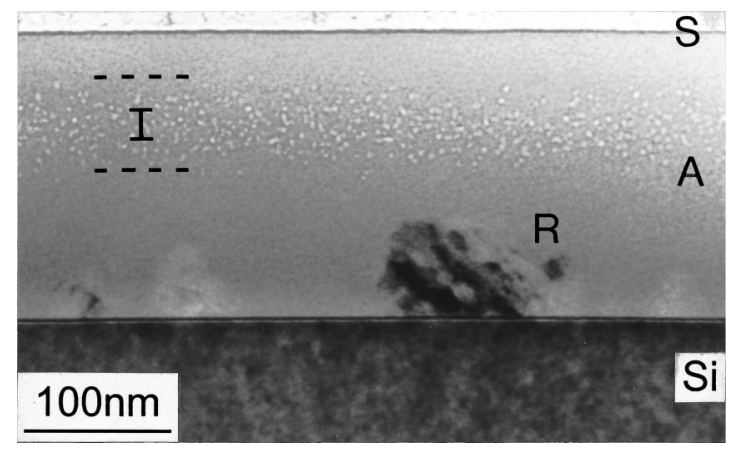

FIG. 2. Cross-section TEM micrograph of an amorphous silicon sample implanted with $5 \times 10^{15} \mathrm{~cm}^{-2} \mathrm{~F}^{+}$and annealed for $30 \mathrm{~s}$ at $675^{\circ} \mathrm{C}$ (S: sample surface, A: amorphous silicon, Si: single-crystal silicon substrate, I: band of fluorine inclusions, and R: recrystallization to polysilicon).

ger effect. For this reason, these points were, therefore, not used in the later calculation of the activation energy.

The $\mathrm{F}$ concentration in the vicinity of the implant peak also remains approximately unchanged as the anneal temperature is increased above $645^{\circ} \mathrm{C}$, and this further suggests that some $\mathrm{F}$ is trapped at damage associated with the ion implantation. Figure 2 shows a TEM micrograph of a sample annealed at $675^{\circ} \mathrm{C}$. The majority of the layer is amorphous, although in some places there is evidence of recrystallization, to polysilicon, of the amorphous Si layer adjacent to the amorphous-layer/single-crystal substrate interface. TEM on samples annealed at lower temperatures showed that no recrystallization had occurred at 600 or $650{ }^{\circ} \mathrm{C}$, whereas at $700^{\circ} \mathrm{C}$, on average $\sim 40 \mathrm{~nm}$ of the amorphous Si layer adjacent to the amorphous-layer/single-crystal substrate interface had recrystallized to polysilicon. The significant recrystallization of the layer at $700{ }^{\circ} \mathrm{C}$, and the similar recrystallization expected at $690^{\circ} \mathrm{C}$, is a further reason for excluding these points in the calculation of the activation energy. In the sample annealed at $675^{\circ} \mathrm{C}$, a band of defects extending from a depth of $\sim 0.03 \mu \mathrm{m}$ to a depth of $\sim 0.09 \mu \mathrm{m}$ can be seen. Comparison with the SIMS profiles shown in Figs. 1(b) and 1(c) shows that the trapped $\mathrm{F}$ and defects occur in the same place in the layer, and the defects are, therefore, thought to be $\mathrm{F}$ inclusions. ${ }^{12}$ Such inclusions also occurred at 650 and $700{ }^{\circ} \mathrm{C}$, but were not observed at $600{ }^{\circ} \mathrm{C}$.

For samples annealed at $645^{\circ} \mathrm{C}$ and above, Eq. (1) was, therefore, fitted to the portion of the profiles lying at depths greater than $\sim 0.1 \mu \mathrm{m}$, and the fits obtained are shown as solid lines in Figs. 1(b) and 1(c). The diffusion coefficients $D_{\mathrm{F}}(T)$ deduced from fitting the Gaussian profile of Eq. (1) to the experimental data, together with a linear fit to the points from 600 to $675^{\circ} \mathrm{C}$ (the points at 690 and $700{ }^{\circ} \mathrm{C}$ are included for completeness only), are shown in an Arrhenius plot in Fig. 3. Vertical error bars represent random errors associated with an uncertainty of $\sim \pm 2.5 \%$ in the SIMS depth scale, and horizontal error bars represent the reproducibility of the RTA set temperature from run to run (typically, $\pm 5^{\circ} \mathrm{C}$ ). From the slope of the fit, an activation energy of $2.2 \pm 0.4 \mathrm{eV}$ for $\mathrm{F}$ transport was calculated, with the uncertainty arising from the accuracy of the linear regression $\left(r^{2}\right.$ $=0.984$ ), the errors in the depth scales, and an uncertainty of $\pm 20^{\circ} \mathrm{C}$ in the absolute RTA temperature. For each further $10^{\circ} \mathrm{C}$ error in the RTA temperature, the value obtained for the activation energy changes by $\sim 2 \%$. An exponential prefo AlP license or copyright, see http://ojps.aip.org/aplo/aplcr.jsp 


\section{Temperature $\left({ }^{\circ} \mathrm{C}\right)$}

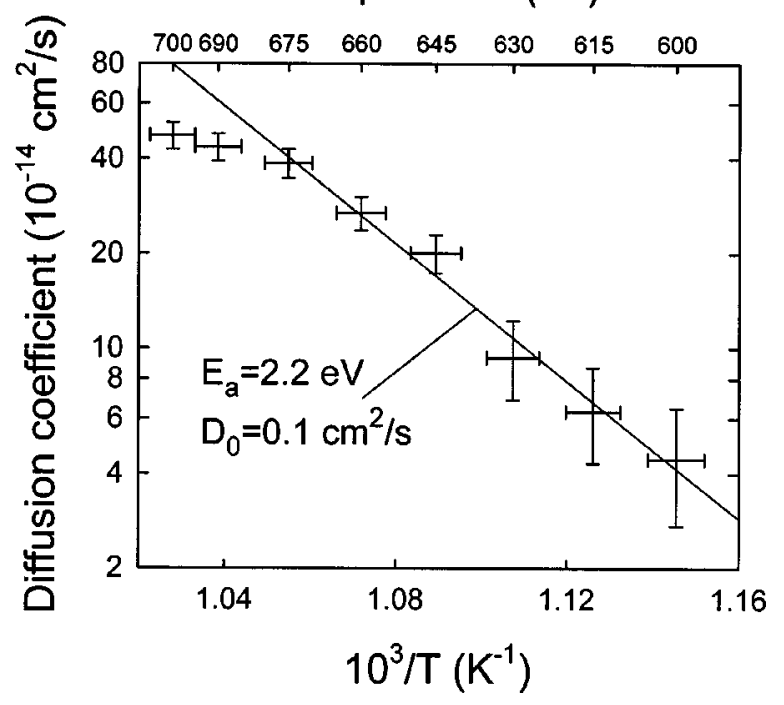

FIG. 3. Arrhenius plot of the diffusion coefficients obtained from fitting the Gaussian profile of Eq. (1) to the experimental data.

actor for $\mathrm{F}$ transport of $\sim 0.1 \mathrm{~cm}^{2} / \mathrm{s}$ was extracted from the intercept of the linear fit to the data points.

At present, $\mathrm{F}$ transport and diffusion in $\mathrm{Si}$ is poorly understood, and direct comparison of different experiments is difficult due to the large range of experimental conditions. In a recent paper, Park and $\mathrm{Kim}^{18}$ implanted $\mathrm{BF}_{2}$ into singlecrystal $\mathrm{Si}$ at $30 \mathrm{keV}$ and extracted an activation energy of $0.16 \mathrm{eV}$ for $\mathrm{F}$ transport. This value is consistent with theoretical calculations, ${ }^{19}$ which showed that the stable state for fluorine in an ideal Si crystal is $\mathrm{F}^{-}$at an interstitial site, with an energy barrier for diffusion of less than $0.7 \mathrm{eV}$. However, it would be expected that $\mathrm{F}$ transport in amorphous, polycrystalline, and single-crystal $\mathrm{Si}$ would be different, as is found for dopants such as As and B. ${ }^{20}$

Although a few F SIMS profiles have been presented for amorphous and polycrystalline silicon, ${ }^{2,12,13,16,21}$ no values of activation energy have been published. Tsai et al. ${ }^{22} \mathrm{im}$ planted $1 \times 10^{15} \mathrm{~cm}^{-2} \mathrm{BF}_{2}$ into a single-crystal $\mathrm{Si}$ sample, which had first been amorphized using a $\mathrm{Si}$ implant, and observed $\mathrm{F}$ redistribution following $30 \mathrm{~min}$ anneals at temperatures in the range $700-1100{ }^{\circ} \mathrm{C}$, which overlaps with the temperature range used in our work. However, no value of the $\mathrm{F}$ diffusion coefficient was given. Marsh et al. ${ }^{12}$ reported an effective $\mathrm{F}$ diffusion coefficient of $\sim 6 \times 10^{-11} \mathrm{~cm}^{-2}$ at $950{ }^{\circ} \mathrm{C}$ for $1 \times 10^{16} \mathrm{~cm}^{-2} \mathrm{~F}$ implanted into polysilicon. This compares to a value of $\sim 15 \times 10^{-11} \mathrm{~cm}^{-2}$ for $\mathrm{F}$ in amorphous silicon at $950^{\circ} \mathrm{C}$ obtained by extrapolation of our Arrhenius plot.
In summary, we have measured $\mathrm{F}$ profiles in amorphous silicon layers implanted with $5 \times 10^{15} \mathrm{~cm}^{-2} \mathrm{~F}$, and rapid thermally annealed for $30 \mathrm{~s}$ at temperatures in the range 600 $700{ }^{\circ} \mathrm{C}$. The measured profiles have been modeled and values of the diffusion coefficient deduced at each anneal temperature. From an Arrhenius plot of the diffusion coefficients, an activation energy for $\mathrm{F}$ transport of $2.2 \pm 0.4 \mathrm{eV}$ was obtained. The SIMS and TEM results show that for anneal temperatures of $645^{\circ} \mathrm{C}$ and above $\mathrm{F}$ is trapped at defects close to the peak of the as-implanted profile.

The authors would like to acknowledge EPSRC for funding this research, and thank Alison Chew for her advice.

${ }^{1}$ J. D. Williams and P. Ashburn, J. Appl. Phys. 72, 3169 (1992).

${ }^{2}$ S. L. Wu, C. L. Lee, T. F. Lei, C. F. Chen, L. J. Chen, K. Z. Ho, and Y. C. Ling, IEEE Electron Device Lett. 15, 120 (1994).

${ }^{3}$ C. D. Marsh, N. E. Moiseiwitsch, G. R. Booker, and P. Ashburn, Inst. Phys. Conf. Ser. 146, 457 (1995).

${ }^{4}$ N. E. Moiseiwitsch, C. Marsh, P. Ashburn, and G. R. Booker, Appl. Phys. Lett. 66, 1918 (1995).

${ }^{5}$ P. J. Wright, N. Kasai, S. Inoue, and K. C. Saraswat, IEEE Electron Device Lett. 10, 347 (1989).

${ }^{6}$ T. Mogami, L. E. G. Johansson, I. Sakai, and M. Fukuma, Tech. Dig. Int. Electron Devices Meet. 91, 533 (1991).

${ }^{7}$ G. S. Virdi, C. M. S. Rauthan, B. C. Pathak, and W. S. Khokle, SolidState Electron. 34, 889 (1991).

${ }^{8}$ T. Kamins, Polycrystalline Silicon for Integrated Circuit Applications (Kluwer Academic, Boston, MA, 1988).

${ }^{9}$ M. Y. Tsai, B. G. Streetman, P. Williams, and C. A. Evans, Appl. Phys. Lett. 32, 144 (1978).

${ }^{10}$ S.-P. Jeng, T.-P. Ma, R. Canteri, M. Anderle, and G. W. Rubloff, Appl. Phys. Lett. 61, 1310 (1992).

${ }^{11}$ Cs. Szeles, B. Nielsen, P. Asoka-Kumar, K. G. Lynn, M. Anderle, T. P. Ma, and G. W. Rubloff, J. Appl. Phys. 76, 3403 (1994).

${ }^{12}$ C. D. Marsh, N. E. Moiseiwitsch, G. R. Booker, and P. Ashburn, J. Appl. Phys. (submitted).

${ }^{13}$ R. G. Wilson, J. Appl. Phys. 54, 6879 (1983).

${ }^{14}$ B. Yu, N. Konuma, E. Arai, Y. Ohji, and Y. Nishioka, J. Appl. Phys. 70, 2408 (1991).

${ }^{15}$ L. Ya. Krasnobaev, N. M. Omelyanovskaya, and V. V. Makarov, J. Appl. Phys. 74, 6020 (1993).

${ }^{16}$ T. P. Chen, T. F. Lei, C. Y. Chang, W. Y. Hsieh, and L. J. Chen, J. Electrochem. Soc. 142, 2000 (1995).

${ }^{17}$ See, for example, S. K. Ghandhi, VLSI Fabrication Principles (Wiley, New York, 1983), p. 345.

${ }^{18}$ Y.-J. Park and J.-J. Kim, J. Appl. Phys. 85, 803 (1999).

${ }^{19}$ C. G. Van de Walle, F. R. McFeely, and S. T. Pantelides, Phys. Rev. Lett. 61, 1867 (1988)

${ }^{20}$ See, for example, K. Park, S. Batra, S. Banerjee, G. Lux, and R. Manukonda, J. Electrochem. Soc. 138, 545 (1991).

${ }^{21}$ H.-H. Tseng, M. Orlowski, P. J. Tobin, and R. L. Hance, IEEE Electron Device Lett. 13, 14 (1992).

${ }^{22}$ M. Y. Tsai, D. S. Day, B. G. Streetman, P. Williams, and C. A. Evans, J. Appl. Phys. 50, 188 (1979). 